\title{
Effects of Acibenzolar-S-Methyl and Ethirimol on the Composition of a Laboratory Population of Barley Powdery Mildew
}

\author{
L. Bousset and J. Pons-Kühnemann
}

First author: INRA, Pathologie Végétale et Epidémiologie, BP01, F-78 850 Thiverval-Grignon, France; and first and second authors: Biometrie und Populationsgenetik, IFZ, Justus Liebig Universität, 35392 Giessen, Germany. Current address of L. Bousset: INRA, UMR Bio3P, BP35327, F-35327 Le Rheu cedex, France. Accepted for publication 13 September 2002.

\begin{abstract}
Bousset, L., and Pons-Kühnemann, J. 2003. Effects of acibenzolar-Smethyl and ethirimol on the composition of a laboratory population of barley powdery mildew. Phytopathology 93:305-315.

To assemble a laboratory population of Blumeria graminis f. sp. hordei for a competition experiment, controlled crosses were performed among 30 parent isolates, which were characterized by their pathotype (i.e., the phenotype observed on a differential set containing lines including host resistance alleles) and their response to the fungicides ethirimol and triadimenol. Variability in the response to the chemical inducer of hostresistance acibenzolar-S-methyl (BTH: benzo[1,2,3]thiadiazole-7carbothioic acid-S-methyl ester) was introduced by using isolates collected in fields repeatedly treated with this chemical. Based on their pathotype and response to ethirimol, 137 isolates recovered from the crosses were chosen to assemble a laboratory population. This protocol produced variability in the laboratory population for traits chosen only in the parents (triadimenol) or both in the parents and the progenies (ethirimol). It was there-
\end{abstract}

ABSTRACT fore postulated that the variability in the response to $\mathrm{BTH}$, if present in the parents, was also present in the laboratory population. No association between these traits was observed. The effect of BTH on the evolution of the laboratory population was compared with the effect of the fungicide ethirimol. The laboratory population was exposed to selection pressures and its evolution was followed over 10 generations. Ethirimol treatments always induced a decrease in sensitivity, whereas no consistent trend was observed for sensitivity to triadimenol (not selected). This result indicates that the application of ethirimol induced a selection pressure. For BTH, (toxicological) sensitivity tests have not detected any consistent evolution, but pathotype diversity indicated that in cases when BTH was applied with ethirimol, BTH induced a further selection pressure in addition to that of ethirimol.

Additional keywords: benzothiadiazole, chemical induced resistance, durability, Erysiphe graminis, relative fitness.
The biotrophic fungus Blumeria graminis (syn. Erysiphe graminis) f. sp. hordei, which causes powdery mildew on barley (Hordeum vulgare), is common throughout the year in many areas of Europe where barley is grown. The fungus is haploid, biotrophic and asexually reproduced, producing wind-dispersed conidia on green leaves of the growing host. It may also complete one annual cycle of sexual reproduction in which cleistothecia are produced on senescent host plants and wind-dispersed ascospores are released in autumn (36). This sexual stage can also be obtained under controlled conditions (5), allowing controlled crosses to be performed.

Disease control measures against barley powdery mildew include the use of resistant cultivars and fungicides. More than 20 resistance alleles have been identified, matched by virulence alleles in the fungus following a gene-for-gene relationship (13). Populations of barley powdery mildew have adapted to all but the mlo (19) resistance alleles used in barley cultivars (11). Largescale use of a specific resistance gene in an area leads to an increase in frequency of the corresponding virulence in the pathogen population, which results in the resistance gene becoming largely ineffective for powdery mildew control in that area (11). Resistance to some fungicides is also controlled by major genes $(1,5)$, and the process of adaptation of the pathogen populations to several groups of fungicides was the same as for host resistance genes (4). To face such a potential for adaptation, it is desirable to

Corresponding author: L. Bousset; E-mail address: bousset@ rennes.inra.fr

Publication no. P-2002-1230-01R

(C) 2003 The American Phytopathological Society identify new means of disease control that do not give rise to strong selection pressure and to evaluate the risk of breakdown prior to their use. Because the ultimate test of durability is largescale use in growing conditions (12), the risk of breakdown might not be intrinsically predictable, but understanding the dynamics of adaptation to disease control measures could suggest strategies to delay that adaptation.

Because they act on the plant and not directly on the pathogen (29), chemicals inducing resistance in the host plant were postulated to be at less risk of a rapid breakdown. For example, Ruess et al. (29) stated that in the case of barley powdery mildew, the inducer BTH seems - due to its particular mode of action-very unlikely to develop resistance in pathogens. This hypothesis should be tested experimentally.

Competition experiments under controlled conditions (25) offer the advantage of precise control of the selection pressure exerted and the composition of the population in the initial generation. However, the composition of the initial (laboratory) population for these experiments, apart from a few studies $(2,15)$, has rarely received much attention. Our objectives were (i) to introduce and randomize the variation in a barley powdery mildew laboratory population, which was done by the use of controlled crosses between selected isolates; (ii) to apply the chemical to be evaluated, which was done by exposing the laboratory population to generations of recurrent selection and comparing the regime to be tested (resistance inducer) to a negative control (no treatment) and a positive control (treatment with the fungicide ethirimol, known to exert a selective pressure); and (iii) to measure the selection pressure, which was done both by following over several generations the sensitivity to the fungicides and the response to BTH (acibenzolar-S-methyl)-induced resistance, as well as by an indicator 
independent of the test used to assess levels of sensitivity of the isolates, i.e., the pathotype diversity in the population.

\section{MATERIALS AND METHODS}

Source of isolates and performance of crosses. Thirty single conidial isolates were chosen as parents for crosses based on their number of virulences, sensitivity to the fungicides ethirimol and triadimenol, response to BTH-induced resistance (9), and mating type when tested (Table 1). Isolates CC52 and DH14 are standard isolates for mating type and reaction to ethirimol (5). Isolates Al1, $\operatorname{Tr} 2$, Ge3, and JEH11, sensitive to DMI fungicides, were provided by E. Limpert (ETH, Zurich, Switzerland). Isolates gl1 and g14, sampled from barley cv. Plaisant growing in untreated farmers' fields in northern France in 1995, had mating type alleles similar to CC52 and DH14, respectively. The remaining 22 isolates were sampled in Giessen, Germany, in four fields of an experiment, including Milgo $\mathrm{E}$ at $25 \%$ of the recommended dose $(280 \mathrm{~g}$ of ethirimol liter ${ }^{-1}, 0.25$ liter $\mathrm{ha}^{-1}$ ) or Bion at the recommended dose $\left(30 \mathrm{~g}\right.$ of BTH ha ${ }^{-1}$ ) (14). BTH-resistant isolates were not available in collections, and it was uncertain whether the test of sensitivity to BTH was reliable. However, it has been observed that when a chemical treatment induces a selection pressure, repeated treatments increase the frequency of insensitive isolates $(6,26,35)$. According to this hypothesis, the source of variation for the sensitivity to BTH was the collection of isolates from field plots treated on four occasions with this chemical during the asexual epidemics. However, the limit of this protocol is that if no evolution is observed during the generations of selection, it is impossible to rule out the hypothesis that the initial population had insufficient variation for the population to evolve. Crosses were carried out in the greenhouse at 10 to $20^{\circ} \mathrm{C}$ according to the method of Brown et al. (5) for several combinations of the 30 isolates (Table 1). Spores were mixed and inoculated on leaves of barley cv. Proctor. Cleistothecia appeared 3 to 4 weeks after the crosses. Ascospore progeny isolates were recovered as described by Brown et al. (5) on leaf segments of barley cv. Pallas. After 7 to 10 days of incubation, conidia from sporulating colonies were transferred to new leaf segments on water agar ( $4 \mathrm{~g}$ of agar and $40 \mathrm{mg}$ of benzimidazole liter $^{-1}$ ).

Isolate characteristics test. Virulence tests were carried out to determine the pathotypes of isolates with respect to the following set of 14 differentials, i.e., near-isogenic lines of barley cv. Pallas (16) (with corresponding resistance genes in parentheses) P01 (Mla1), P02 (Mla3), P03 (Mla6), P05B (Mla7), P08B (Mla9), P09 (Mla10), P10 (Mla12), P11 (Mla13), P12 (Mla22), P16 (Mlk1), P21 (Mlg), P23 (MlLa), and P24 (Mlh) and cv. Lotta (MlAb) (18). Each isolate was inoculated with a settling tower on leaf segments of 10-day-old seedlings of barley cv. Pallas near-isogenic lines maintained on water agar. After 7 days of incubation $\left(18^{\circ} \mathrm{C}, 16 \mathrm{~h}\right.$ light, $1 \mathrm{klx}$ ), the infection types (IT) were scored on a 0 -to- 4 scale (20) and classified as avirulent (IT = 0 to 3 ) or virulent (IT = 4).

For fungicide sensitivity tests, the plants were prepared by seed treatment. Seeds of barley cv. Pallas were treated with fungicide by mixing them thoroughly with ethirimol formulated as the liquid Milstem (51.3\% ethirimol) or with triadimenol formulated as the liquid Baytan (75 g of triadimenol, $10 \mathrm{~g}$ of imazalil, and $9 \mathrm{~g}$ of fuberidazol liter $\left.{ }^{-1}\right)$. BTH, formulated as Bion (50\% acibenzolar-S-

TABLE 1. Virulence pathotype and response to fungicides of 30 Blumeria graminis f. sp. hordei single spore isolates used as parents for the crosses ${ }^{\mathrm{w}}$

\begin{tabular}{|c|c|c|c|c|c|c|c|c|c|c|c|c|c|c|c|c|c|c|c|c|c|c|c|c|c|c|}
\hline \multirow[b]{2}{*}{ Isolate } & \multicolumn{14}{|c|}{ Virulence pathotype ${ }^{\mathrm{x}}$} & \multicolumn{3}{|c|}{ Fungicides $^{\mathrm{y}}$} & \multicolumn{9}{|c|}{ Crosses $^{\mathrm{z}}$} \\
\hline & $\mathrm{V}_{\mathrm{a} 1}$ & $\mathrm{~V}_{\mathrm{a} 3}$ & $\mathrm{~V}_{\mathrm{a} 6}$ & $\mathrm{~V}_{\mathrm{a} 7}$ & $\mathrm{~V}_{\mathrm{a} 9}$ & $\mathrm{~V}_{\mathrm{a} 10}$ & $\mathrm{~V}_{\mathrm{a} 12}$ & $\mathrm{~V}_{\mathrm{a} 13}$ & $\mathrm{~V}_{\mathrm{a} 22}$ & $\mathrm{~V}_{\mathrm{k} 1}$ & $\mathrm{~V}_{\mathrm{g}}$ & $\mathrm{V}_{\mathrm{La}}$ & $\mathrm{V}_{\mathrm{h}}$ & $\mathrm{V}_{\mathrm{Ab}}$ & Eth & Tdl & Bth & 1 & 2 & 3 & 4 & 5 & 6 & 7 & 8 & 9 \\
\hline $\mathrm{CC52}$ & 0 & 0 & 0 & 1 & 1 & 1 & 1 & 1 & 0 & 1 & 1 & 0 & 1 & 0 & $\mathrm{~S}$ & $\mathrm{~S}$ & $\mathrm{R}$ & 0 & 0 & 0 & 0 & 0 & 0 & + & + & 0 \\
\hline DH14 & 0 & 0 & 0 & 0 & 0 & 1 & 0 & 0 & 1 & 1 & 1 & 0 & 0 & 0 & $\mathrm{R}$ & $\mathrm{S}$ & $\mathrm{R}$ & 0 & 0 & 0 & 0 & 0 & 0 & + & + & 0 \\
\hline Al1 & 1 & 0 & 0 & 0 & 0 & 0 & 1 & 0 & 1 & 0 & 0 & 0 & 0 & 0 & $\mathrm{~S}$ & $\mathrm{~S}$ & $\mathrm{R}$ & 0 & 0 & 0 & 0 & + & + & 0 & + & 0 \\
\hline $\operatorname{Tr} 2$ & 0 & 1 & 0 & 1 & 1 & 1 & 1 & 0 & 1 & 1 & 1 & 1 & 1 & 0 & $\mathrm{~S}$ & $\mathrm{~S}$ & $\mathrm{~S}$ & 0 & 0 & 0 & 0 & + & + & 0 & + & 0 \\
\hline Ge3 & 0 & 0 & 1 & 0 & 0 & 0 & 0 & 0 & 1 & 1 & 1 & 0 & 1 & 0 & $\mathrm{R}$ & $\mathrm{S}$ & $\mathrm{S}$ & 0 & 0 & 0 & 0 & + & + & 0 & + & 0 \\
\hline JEH11 & 0 & 0 & 0 & 1 & 1 & 1 & 0 & 0 & 0 & 1 & 0 & 1 & 1 & 0 & $\mathrm{~S}$ & $\mathrm{~S}$ & $\mathrm{R}$ & 0 & 0 & 0 & 0 & + & + & 0 & + & 0 \\
\hline gl1 & 0 & 0 & 0 & 0 & 0 & 0 & 0 & 0 & 1 & 0 & 0 & 0 & 1 & 0 & $\mathrm{R}$ & $\mathrm{R}$ & $\mathrm{S}$ & 0 & 0 & 0 & 0 & 0 & 0 & + & + & 0 \\
\hline g14 & 0 & 0 & 0 & 0 & 0 & 0 & 0 & 0 & 1 & 0 & 0 & 0 & 1 & 0 & $\mathrm{R}$ & $\mathrm{R}$ & $\mathrm{md}$ & 0 & 0 & 0 & 0 & 0 & 0 & + & + & 0 \\
\hline BH1 & 0 & 0 & 1 & 1 & 1 & 1 & 0 & 0 & 0 & 1 & 0 & 1 & 1 & 1 & $\mathrm{~S}$ & $\mathrm{R}$ & $\mathrm{R}$ & + & + & + & 0 & + & + & + & + & + \\
\hline $\mathrm{BH} 2$ & 0 & 0 & 1 & 0 & 0 & 0 & 0 & 0 & 1 & 1 & 0 & 1 & 1 & 0 & $\mathrm{R}$ & $\mathrm{R}$ & $\mathrm{R}$ & + & + & + & 0 & + & + & + & + & + \\
\hline BH3 & 0 & 1 & 1 & 1 & 0 & 0 & 0 & 0 & 1 & 0 & 0 & 1 & 1 & 0 & $\mathrm{~S}$ & $\mathrm{R}$ & $\mathrm{R}$ & + & + & + & 0 & + & + & + & + & + \\
\hline BH4 & md & $\mathrm{md}$ & md & md & md & md & md & $\mathrm{md}$ & md & md & $\mathrm{md}$ & md & $\mathrm{md}$ & $\mathrm{md}$ & $\mathrm{md}$ & $\mathrm{md}$ & $\mathrm{md}$ & + & + & + & 0 & + & + & + & + & + \\
\hline BH5 & 0 & 1 & 1 & 1 & 0 & 1 & 0 & 1 & 1 & 1 & 1 & 1 & 1 & 0 & $\mathrm{~S}$ & $\mathrm{R}$ & $\mathrm{R}$ & + & + & + & 0 & + & + & + & + & + \\
\hline BL1 & 0 & 0 & 1 & 1 & 1 & 1 & 1 & 0 & 0 & 1 & 1 & 0 & 1 & 0 & $S$ & $\mathrm{R}$ & $\mathrm{R}$ & + & + & 0 & + & + & + & + & + & + \\
\hline BL2 & 1 & 0 & 1 & 1 & 0 & 0 & 0 & 0 & 1 & 1 & 0 & 1 & 1 & 0 & $\mathrm{~S}$ & $\mathrm{M}$ & $\mathrm{R}$ & + & + & 0 & + & + & + & + & + & + \\
\hline BL3 & 0 & 0 & 1 & 0 & 0 & 0 & 1 & 0 & 1 & 1 & 0 & 1 & 1 & 0 & $\mathrm{~S}$ & $\mathrm{R}$ & $\mathrm{R}$ & + & + & 0 & + & + & + & + & + & + \\
\hline BL4 & 0 & 0 & 1 & 1 & 0 & 1 & 0 & 0 & 0 & 1 & 0 & 0 & 1 & 0 & $\mathrm{~S}$ & $\mathrm{R}$ & $\mathrm{R}$ & + & + & 0 & + & + & + & + & + & + \\
\hline FH1 & 0 & 0 & 0 & 1 & 1 & 1 & 1 & 1 & 0 & 1 & 1 & 0 & 1 & 0 & $\mathrm{R}$ & $\mathrm{R}$ & $\mathrm{R}$ & + & 0 & + & + & 0 & + & + & + & + \\
\hline $\mathrm{FH} 2$ & $\mathrm{md}$ & $\mathrm{md}$ & md & $\mathrm{md}$ & $\mathrm{md}$ & $\mathrm{md}$ & $\mathrm{md}$ & $\mathrm{md}$ & $\mathrm{md}$ & $\mathrm{md}$ & $\mathrm{md}$ & $\mathrm{md}$ & $\mathrm{md}$ & $\mathrm{md}$ & $\mathrm{md}$ & $\mathrm{md}$ & $\mathrm{md}$ & + & 0 & + & + & 0 & + & + & + & + \\
\hline $\mathrm{FH} 3$ & 1 & 0 & 1 & 1 & 0 & 1 & 1 & 0 & 1 & 1 & 0 & 0 & 1 & 0 & $\mathrm{~S}$ & $\mathrm{M}$ & $\mathrm{R}$ & + & 0 & + & + & 0 & + & + & + & + \\
\hline FL1 & 0 & 0 & 1 & 1 & 0 & 1 & 1 & 0 & 0 & 1 & 0 & 1 & 1 & 1 & $\mathrm{~S}$ & $\mathrm{R}$ & $\mathrm{R}$ & 0 & + & + & + & 0 & + & + & + & + \\
\hline FL2 & 1 & 0 & 1 & 1 & 0 & 1 & 0 & 0 & 0 & 1 & 1 & 1 & 1 & 0 & $\mathrm{~S}$ & $\mathrm{R}$ & $\mathrm{R}$ & 0 & + & + & + & 0 & + & + & + & + \\
\hline FL3 & md & $\mathrm{md}$ & md & $\mathrm{md}$ & $\mathrm{md}$ & $\mathrm{md}$ & $\mathrm{md}$ & $\mathrm{md}$ & $\mathrm{md}$ & $\mathrm{md}$ & $\mathrm{md}$ & md & $\mathrm{md}$ & $\mathrm{md}$ & $\mathrm{md}$ & $\mathrm{md}$ & $\mathrm{md}$ & 0 & + & + & + & 0 & + & + & + & + \\
\hline FL4 & 0 & 0 & 1 & 0 & 0 & 0 & 0 & 0 & 1 & 1 & 0 & 0 & 1 & 0 & $\mathrm{~S}$ & $\mathrm{~S}$ & $\mathrm{~S}$ & 0 & + & + & + & 0 & + & + & + & + \\
\hline FL5 & 0 & 1 & 1 & 1 & 0 & 0 & 0 & 0 & 1 & 1 & 0 & 1 & 1 & 0 & $S$ & M & $\mathrm{R}$ & 0 & + & + & + & 0 & + & + & + & + \\
\hline FL6 & 0 & 0 & 1 & 1 & 1 & 1 & 0 & 1 & 0 & 1 & 0 & 1 & 1 & 1 & $\mathrm{~S}$ & $\mathrm{R}$ & $\mathrm{R}$ & 0 & + & + & + & 0 & + & + & + & + \\
\hline VH1 & 0 & 0 & 1 & 1 & 1 & 1 & 1 & 1 & 0 & 1 & 1 & 0 & 1 & 1 & $\mathrm{~S}$ & $\mathrm{R}$ & $\mathrm{md}$ & + & + & + & + & 0 & + & + & + & 0 \\
\hline $\mathrm{VH} 2$ & 0 & 1 & 1 & 1 & 1 & 0 & 1 & 0 & 1 & 1 & 1 & 1 & 1 & 0 & $\mathrm{~S}$ & $\mathrm{R}$ & $\mathrm{S}$ & + & + & + & + & 0 & + & + & + & 0 \\
\hline VL1 & 0 & 0 & 1 & 1 & 0 & 1 & 0 & 0 & 0 & 0 & 0 & 0 & 1 & 0 & $\mathrm{R}$ & M & $\mathrm{R}$ & + & + & + & + & 0 & + & + & + & 0 \\
\hline VL2 & 0 & 0 & 1 & 0 & 0 & 0 & 0 & 0 & 1 & 0 & 0 & 0 & 1 & 0 & $\mathrm{~S}$ & M & $\mathrm{R}$ & + & + & + & + & 0 & + & + & + & 0 \\
\hline
\end{tabular}

${ }^{\mathrm{w}} \mathrm{md}=$ missing data.

${ }^{x} 0$ indicates avirulence and 1 indicates virulence of the isolate on the corresponding host resistance allele.

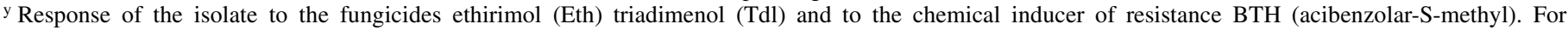
ethirimol, S indicates sensitivity as the standard isolate CC52 and R indicates resistance as the standard isolate DH14. For triadimenol, S indicates sensitivity as the standard isolates DH14 and CC66, M indicates moderate resistance as the standard isolate CC107, and R indicates high resistance as the standard isolate E1. For BTH, where the genetics of the resistance were not known and no standard isolates were available, the two arbitrary response categories S and R indicate lower and higher resistance, respectively, than the mean of the four isolates CC52, CC107, DH14, and E1.

${ }^{\mathrm{z}}+$ indicates that the corresponding isolate was included in the cross, whereas 0 indicates that it was not included. 
methyl), was applied by spraying seedling leaves $48 \mathrm{~h}$ before inoculation with a hand-held sprayer at a volume rate of $5.56 \times$ $10^{3}$ liter ha ${ }^{-1}$. All tests included one set of plants untreated (Milstem, Baytan) or sprayed with water only (Bion). Milstem was applied at 12 doses $(2.6,4.6,8.1,14.4,25.5,45.3,80.5,142.9$, 233.7, 450.3, 799, and 1,418 mg of ethirimol $\mathrm{kg}^{-1}$ of seeds). Baytan was applied at 12 doses $(29.5,37.1,46.8,59,74.3,93.7$, $118,148.7,187.4,236.2,297.6$, and $375 \mathrm{mg}$ of triadimenol $\mathrm{kg}^{-1}$ of seeds) and Bion was applied at 12 doses $(0.6,1,1.7,3,5.3,9.5$, $16.8,30,53.4,95,19.2$, and $300 \mathrm{~g}$ of BTH ha ${ }^{-1}$ in $10 \mathrm{ml}$ of water). The number and spacing of the doses were chosen such that the parents were resistant to the lowest dose and sensitive to the highest dose, and so the standard isolates could be reliably distinguished. Recommended doses are $7 \mathrm{ml}$ of Milstem $\mathrm{kg}^{-1}$ of seeds $(3,591 \mathrm{mg}$ of ethirimol kg-1 of seeds), $5 \mathrm{ml}$ of Baytan $\mathrm{kg}^{-1}$ of seeds $(375 \mathrm{mg}$ of triadimenol $\mathrm{kg}^{-1}$ of seeds), and $30 \mathrm{ml}$ of BTH ha-1 in 200 to 400 liters of water.

Tests of fungicide sensitivity and response to BTH-induced resistance were performed on detached leaf segments. Using a settling tower, each single isolate was inoculated onto leaf segments of 10-day-old seedlings maintained on water agar. Two replicates of each dose and the untreated control were used to test each isolate. The number of mildew colonies formed on the leaf segments were assessed 7 days after inoculation. Isolates were tested over several days along with isolates covering the two levels of response to ethirimol CC52 (sensitive) and DH14 (resistant) and four levels of response to triadimenol DH14 (sensitive), CC66 (low), CC107 (moderate), and E1 (high) as standards in each test $(1,5)$. Because the levels of response to BTH were unknown and no standards were available, isolates DH14, CC66, CC107, and E1 were always included.

Assembling a laboratory population. One hundred thirtyseven isolates were chosen from a total of two hundred thirtythree progeny issued from the crosses such that (i) each pathotype was represented only by one isolate and therefore corresponded to a single genotype, (ii) some variation for the response to ethirimol was present in the population, i.e., isolates sensitive as CC52 and resistant as DH14 would be present, and (iii) some variation for the response to BTH was present in the population. The sensitivity to BTH (expected to be variable in the parents of the crosses) was assessed on the ascospores, but due to the test, the sensitivity could not be reliably used at this step as a criterion to choose the ascospore progenies. However, it was checked using another trait (sensitivity to triadimenol) so that when variation was present in the parent of the crosses, some of this variation was present in the ascospore population, even if the ascospores were not chosen according to their level of response to the trait.

To ensure that all isolates were present in approximately equal frequencies in the laboratory population in the initial generation $\left(\mathrm{G}_{0}\right)$, which was a prerequisite to allow comparison between treatments, spores from a single colony were blown individually for each of the 137 isolates into each generation box $(25 \times 50 \times 25 \mathrm{~cm}$ [width $\times$ length $\times$ height] transparent box, covered by a glass plate).

Successive generations under selection pressure. Generation boxes were sown with $30 \mathrm{~g}$ (approximately 700 seeds) of barley cv. Pallas seeds 7 days before inoculation and placed in a growing chamber $\left(18^{\circ} \mathrm{C}, 16 \mathrm{~h}\right.$ light, $\left.2.5 \mathrm{klx}\right)$. After inoculation, a generation box was incubated in another chamber $\left(18^{\circ} \mathrm{C}, 16 \mathrm{~h}\right.$ light, $2 \mathrm{klx}$ ) for 6 days at which point 20 leaves chosen to bear 50 to 100 powdery mildew colonies each were cut, placed on water agar, and further incubated for $24 \mathrm{~h}$ to allow spore accumulation. The spores from the 20 leaves collected from one generation box were blown into a new generation box with 7-day-old seedlings. This was repeated for 10 generations.

Five selection regimes were applied (two replications each) for a total of 10 generation boxes. The BTH inducer was applied in two regimes, either alone (B) or as BTH in combination with ethirimol (EB). One negative control regime received no treatment
(C). Two positive control regimes were applied with ethirimol (E) and ethirimol with a selection pressure attenuated by allowing $10 \%$ of the population to escape from the treatment (ES). The negative control was included to check the absence of evolution of the traits when no selection pressure was applied, and the positive controls were included to check that the protocol used allowed the detection of changes in the composition of the population specifically induced by a selection pressure. Ethirimol, formulated as liquid Milstem (51.3\%, wt/wt ethirimol), was applied by seed treatment at a dose of $14.4 \mathrm{mg}$ of ethirimol kg-1 of seeds. BTH formulated as Bion (50\% acibenzolar-S-methyl) was applied by spraying $48 \mathrm{~h}$ before inoculation at the recommended dose of $30 \mathrm{~g}$ $\mathrm{ha}^{-1}$ in $20 \mathrm{ml}$ of water. The regime simulating escape (ES) from the fungicide treatment was applied by sowing $90 \%$ of ethirimoltreated seeds and $10 \%$ of untreated seeds (two $8-\times 8-\mathrm{cm}$ pots, each with $1.5 \mathrm{~g}$ of seeds); one leaf was cut from each of the two pots for the next generation.

Sampling was performed at the end of $G_{0}$ and every other generation. Leaf segments bearing colonies at low density were cut 6 days after inoculation, placed on water agar, and incubated for $24 \mathrm{~h}$. Spores from individual colonies were transferred onto new leaf segments with a toothpick. These isolates were tested for virulence as described previously to identify the actual pathotype frequencies for a given generation. The 137 pathotypes, each represented by a single genotype, were initially mixed in approximately equal frequencies.

Analysis of the toxicological tests. In order to quantify the response to the fungicides and to $\mathrm{BTH}$ for each isolate, the logarithm of the median effective dose $\left(\mathrm{ED}_{50}\right)$, i.e., the dose reducing the number of colonies by about $50 \%$ compared with the untreated control, was estimated for each of the three chemicals. This was done by Probit analysis on the responses on the different doses, i.e., the mean number of mildew colonies formed on the two leaf segments, out of the total number of colonies, i.e., the mean of colony numbers on the untreated leaf segments. However, as described by Brown and Wolfe (6), this method of fitting a regression model to the data to calculate the individual $\log \mathrm{ED}_{50}$ requires assumptions about the underlying distribution of effective doses and the distribution of fungicide in treated host plants. These assumptions may be violated for many pathogens, including barley powdery mildew, and for chemicals which only become toxic after modification by the plant. In some cases, model-fitting produces results which clearly do not represent the true response of the pathogen to the chemical. It can be difficult to estimate effective doses for isolates with very high or low resistance and to compare isolates in different batches of tests (6).

To remedy this potential problem, the variation in the data was displayed by principal component analysis (PCA) $(3,6)$. The first aim of PCA is to find a small number of variables that account for as much as possible of the total variation in the data, thus allowing the complete data to be described by just a few $Z$-variables $(3,6)$. From the $p$ original variables $X 1, X 2, \ldots, X p$, which may be correlated with each other, an equal number of new uncorrelated variables $Z 1, Z 2, \ldots, Z p$ is produced. The new variables are ordered so that $Z 1$ is the single variable that accounts for the largest part of the variation in the data, $Z 2$ is the next most informative variable, and so on. The second aim of PCA is to describe the relationship of individuals to one another, which is simplified by using a small number of variables in order to group the isolates according to levels of response similar to the response of well-characterized standard isolates $(3,6)$. For each test batch and each of the three chemicals, the mean colony number on the different doses divided by mean colony number on untreated leaves were regarded as variables, and each isolate was regarded as an observation. PCA was carried out on the correlation matrix of $Z$-transformed variables, excluding the data from untreated leaves. In order to display the variation of the isolates in relation to the extracted principal components, observations (isolates) were projected onto the first 
two principal components $(Z 1, Z 2)$. Within each test batch, the isolates were allocated to categories of fungicide sensitivity by comparison of their score on the first principal component (Z1) with the score of the reference isolates used in the same test.

To assess the correlation between the two methods, for each of the chemicals, the Pearson correlation coefficient was calculated
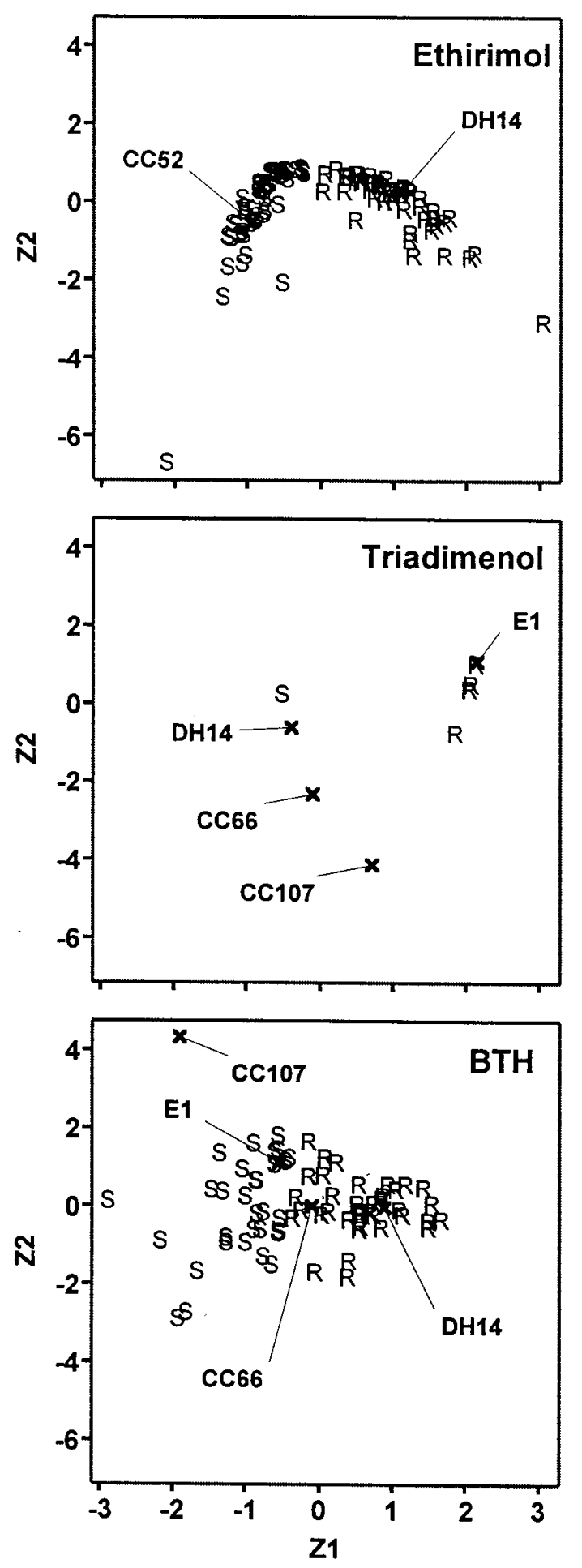

Fig. 1. Principal component analysis using the response of the isolates to 12 doses of the active compounds as variables gives a good discrimination of the standard isolates, and allows a classification of the tested isolates into categories of response similar to the standard isolates. Scores of the isolates on the two principal components $(Z 1, Z 2)$ are illustrated for three batches of tests of the response to ethirimol, triadimenol, and BTH. Sensitive (S), resistant $(\mathrm{R})$, or intermediate $(\mathrm{M})$ standard isolates are indicated for each category of response. between the first principal component $(Z 1)$ of the PCA and the effective doses.

From $\mathrm{G}_{0}$ and every other generation thereafter, pathotypes were assessed using a sample of isolates from each generation box. As each pathotype was represented by a single genotype in the laboratory population, virulence tests were used to identify pathotypes (=genotypes), whose response to ethirimol, triadimenol and BTH had been characterized before the start of the experiment. To assess changes in the population composition under different selection regimes in successive generations, the number of isolates in the two (ethirimol, BTH) or three categories (triadimenol) were determined every second generation. From these data, relative fitness $(2,17)$ was estimated based on the changes of absolute frequencies in successive samples by means of a generalized linear model assuming a multinomial distribution (24) followed by a likelihood ratio test (or G-test).

Diversity indices. In surveys of natural populations (28), field experiments (34) and competition experiments $(15,22)$, selection pressure has been found to cause a decrease in the diversity of pathogen populations, whereby the magnitude of the decrease depended on the strength of the selection applied. We therefore used the changes in diversity over generations as an indirect indicator of the occurrence of a selection event. Because our population was a mixture of a given number of pathotypes, frequencies of which were assessed over generations, diversity indices based on pathotype frequencies were selected over indices based on allele frequencies.

The modified Shannon diversity index $\mathrm{Hw}^{\prime}$, i.e., the normalized version of Shannon's H (30), obtained by division through $\ln (N)$ and less sensitive to sample size (8), was calculated using the observed pathotype frequencies as follows

$$
\mathrm{Hw}^{\prime}=-\frac{1}{\ln (N)} \times \sum_{i=1}^{m}\left(\frac{n_{i}}{N}\right) \ln \left(\frac{n_{i}}{N}\right)
$$

where $N=$ sample size, $n_{i}=$ number of isolates of the $i$ th pathotype, and $m=$ number of pathotypes.

The Shannon evenness index EH, i.e., the normalized version of Shannon's H, obtained by division through $H_{\max }=\ln (m)$, was caculated as follows

$$
\mathrm{EH}=-\frac{1}{\ln (m)} \times \sum_{i=1}^{m}\left(\frac{n_{i}}{N}\right) \ln \left(\frac{n_{i}}{N}\right)
$$

The Simpson diversity index $\lambda(32)$, i.e., the probability of obtaining two distinct pathotypes when randomly drawing two isolates from the sample, was calculated as follows

$$
\lambda=1-\sum_{i=1}^{m}\left(\frac{n_{i}\left(n_{i}-1\right)}{N(N-1)}\right)
$$

Pseudovalues of the diversity indices and their confidence intervals based on estimates of the standard error were obtained by the jackknife (resampling) procedure $(27,33)$. Pseudovalues were analyzed using a general linear model (GLM) with generation and selection regime as factors. For all indices, the factors were significant $(P=0.05)$, whereas interactions between factors were not significant. After the overall $F$ test had shown significance, a post hoc multiple-comparison test was applied. Because the variances were unequal (according to Levene's test of equality of error variances), Dunnett's T3 (pairwise comparison test based on the studentized maximum modulus) was applied. All statistical analyses were carried out by using the statistical package SPSS (version 10.0.7; SPSS Inc., Chicago).

\section{RESULTS}

Fungicide tests and PCA. For the response to ethirimol, for each of the test batches, the scores for the first two principal components $(Z 1, Z 2)$ allowed the separation of the response of the 
control isolates CC52 and DH14, as illustrated for one test batch (Fig. 1). In all cases, $Z 1$ accounted for a major part of the variation, between 46 and $74 \%$ of the total (Table 2), and the scores for $Z 1$ were related to the resistance to ethirimol. Increasing scores for $Z 1$ reflected higher levels of resistance of different isolates to ethirimol, indicated by the position of the control isolates on the graph (Fig. 1) and the high value of the Pearson correlation coefficient $(0.97 ; P=0.001)$ between $Z 1$ scores and $\log \mathrm{ED}_{50}$ values. For each test, the tested isolates were grouped in two distinct clouds around the control isolates, which allowed the tested isolates to be placed in one of the categories of resistance. For each test, the mean value of the $Z 1$ scores of the two control isolates was used for the classification of the tested isolates into the two categories (Table 2). All the tested parents and the 137 selected progeny isolates from the crosses could be placed into one of two distinct classes: either resistant, with a level of response similar to that of the resistant control DH14, or sensitive, similar to the sensitive control CC52. The relative position of the control isolates was consistent across the batches of test, and therefore, the results (classification of the tested isolates as either resistant or sensitive) from the different test batches could be combined.

For the response to triadimenol, the four control isolates were separated by their scores on the first two principal components $(Z 1, Z 2)$ of the PCA as illustrated for one test batch (Fig. 1). Again, $Z 1$ accounted for a major part of the variation: between 58

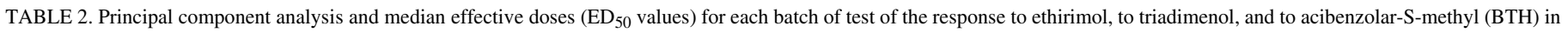
the initial population and standard isolates

\begin{tabular}{|c|c|c|c|c|c|c|c|c|c|c|c|c|c|c|c|c|c|c|c|c|c|c|}
\hline & \multicolumn{10}{|c|}{ Response to ethirimol } & \multicolumn{8}{|c|}{ Response to triadimenol } & \multicolumn{4}{|c|}{ Response to BTH } \\
\hline & \multicolumn{2}{|c|}{ Eth-1 } & \multicolumn{2}{|c|}{ Eth-2 } & \multicolumn{2}{|c|}{ Eth-3 } & \multicolumn{2}{|c|}{ Eth-4 } & \multicolumn{2}{|c|}{ Eth-5 } & \multicolumn{2}{|c|}{ Tdl-1 } & \multicolumn{2}{|c|}{ Tdl-2 } & \multicolumn{2}{|c|}{ Tdl-3 } & \multicolumn{2}{|c|}{ Tdl-4 } & \multicolumn{2}{|c|}{ Bth-1 } & \multicolumn{2}{|c|}{ Bth-2 } \\
\hline & $Z 1$ & $Z 2$ & $Z 1$ & $Z 2$ & $Z 1$ & $Z 2$ & $Z 1$ & $Z 2$ & $Z 1$ & $Z 2$ & $Z 1$ & $Z 2$ & $Z 1$ & $Z 2$ & $Z 1$ & $Z 2$ & $Z 1$ & $Z 2$ & $Z 1$ & $Z 2$ & $Z 1$ & $Z 2$ \\
\hline \multicolumn{23}{|c|}{$\%$ Variation and eigenvalue ${ }^{\mathrm{x}}$} \\
\hline Eigenvalue & 6.14 & 2.14 & 6.35 & 1.41 & 5.50 & 1.69 & 6.99 & 2.55 & 8.84 & 3.16 & 8.53 & 2.48 & 6.99 & 3.07 & 10.0 & 1.59 & 11.3 & 0.48 & 7.71 & 1.74 & 7.20 & 2.08 \\
\hline$\%$ & 51.2 & 17.8 & 52.9 & 11.7 & 45.8 & 14.1 & 58.3 & 21.3 & 73.7 & 26.3 & 71.1 & 20.7 & 58.2 & 25.6 & 83.7 & 13.2 & 94.4 & 4.0 & 64.3 & 14.5 & 60.0 & 17.4 \\
\hline \multicolumn{23}{|c|}{ Score loadings ${ }^{\mathrm{y}}$} \\
\hline CC52 & -0.65 & -0.54 & -0.28 & 0.88 & -0.96 & -0.54 & -0.31 & 0.65 & -0.44 & -1.07 & $\ldots$ & $\ldots$ & $\ldots$ & $\ldots$ & $\ldots$ & $\ldots$ & $\ldots$ & $\ldots$ & $\ldots$ & $\ldots$ & $\ldots$ & $\ldots$ \\
\hline DH14 & 1.89 & -2.02 & 0.91 & 0.36 & 1.10 & 0.28 & 1.90 & -0.49 & 1.14 & 0.15 & -1.50 & 1.10 & -1.84 & 1.52 & -0.32 & 0.05 & -0.38 & -0.59 & 0.90 & -0.03 & 0.85 & 0.33 \\
\hline CC66 & $\ldots$ & $\ldots$ & $\ldots$ & $\ldots$ & $\ldots$ & $\ldots$ & $\ldots$ & $\ldots$ & $\ldots$ & $\ldots$ & -1.53 & 1.18 & -1.84 & 1.52 & -0.23 & 0.49 & -0.09 & -2.32 & -0.10 & 0.03 & 1.23 & -0.86 \\
\hline $\mathrm{CC} 107$ & $\ldots$ & $\ldots$ & $\ldots$ & $\ldots$ & $\ldots$ & $\ldots$ & $\ldots$ & $\ldots$ & $\ldots$ & $\ldots$ & -0.96 & -0.04 & -1.65 & 1.19 & 0.33 & 2.84 & 0.71 & -4.10 & -1.91 & 4.32 & -1.24 & -5.52 \\
\hline E1 & $\ldots$ & $\ldots$ & $\ldots$ & $\ldots$ & $\ldots$ & $\ldots$ & $\ldots$ & $\ldots$ & $\ldots$ & $\ldots$ & 0.87 & 0.23 & 0.02 & -0.66 & 2.94 & -0.65 & 2.15 & 1.13 & -0.54 & 1.11 & -0.59 & -0.92 \\
\hline \multicolumn{23}{|c|}{ Log $\mathrm{ED}_{50}$ values ${ }^{\mathrm{z}}$} \\
\hline CC52 (S) & 1.35 & (22) & 1.49 & (31) & 1.18 & (15) & 1.67 & (47) & 1.60 & (40) & $\ldots$ & $\ldots$ & $\ldots$ & $\ldots$ & $\ldots$ & $\ldots$ & $\ldots$ & $\ldots$ & $\ldots$ & $\ldots$ & $\ldots$ & $\ldots$ \\
\hline DH14 (R) & 2.23 & (170) & 2.10 & (126) & 2.36 & (229) & 3.06 & $(1,148)$ & 2.69 & (490) & 0.94 & (9) & 0.89 & (8) & 1.16 & (15) & 1.18 & (15) & 1.61 & (41) & 2.73 & (537) \\
\hline CC66 & $\ldots$ & $\ldots$ & $\ldots$ & $\ldots$ & $\ldots$ & $\ldots$ & $\ldots$ & $\ldots$ & $\ldots$ & $\ldots$ & 0.89 & (8) & 0.89 & (8) & 1.47 & (30) & 1.58 & (38) & 2.15 & (141) & 2.61 & (407) \\
\hline CC107 & $\ldots$ & $\ldots$ & $\ldots$ & $\ldots$ & $\ldots$ & $\ldots$ & $\ldots$ & $\ldots$ & $\ldots$ & $\ldots$ & 1.64 & (44) & 1.13 & (14) & 1.81 & (65) & 1.99 & (98) & 3.24 & $(1,738)$ & 2.82 & (661) \\
\hline E1 & $\ldots$ & $\ldots$ & $\ldots$ & $\ldots$ & $\ldots$ & $\ldots$ & $\ldots$ & $\ldots$ & $\ldots$ & $\ldots$ & 2.54 & (347) & 2.05 & (112) & 2.55 & (355) & 3.31 & $(2,042)$ & 2.46 & (288) & 3.76 & $(5,754)$ \\
\hline
\end{tabular}

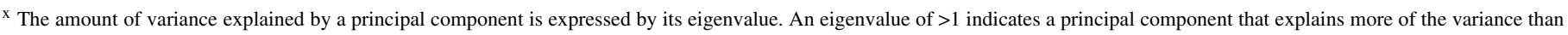
one of the original variables. Percentage of the variation (\%) is calculated by the eigenvalue of the appropriate principal component divided by the sum of all eigenvalues.

$\mathrm{y}$ The score loadings gives the position of an observation (isolate) projected onto the first two principal components.

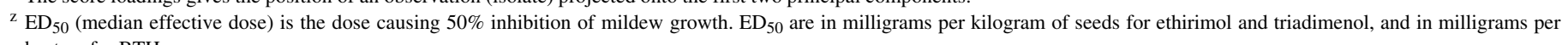
hectare for BTH.
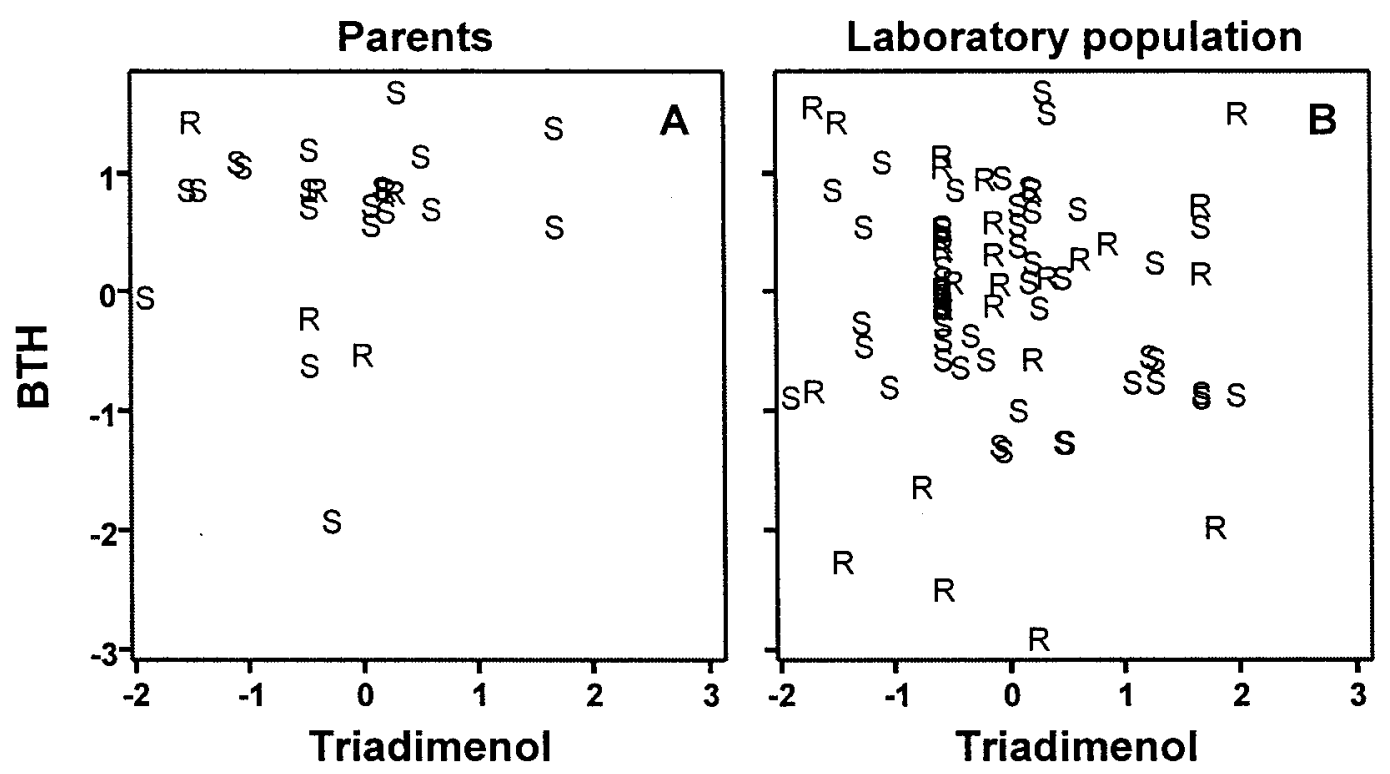

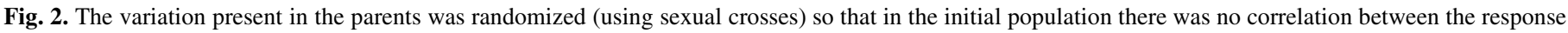

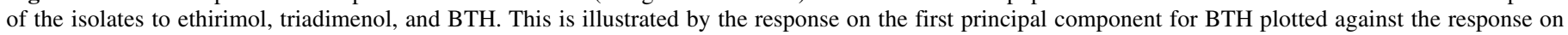

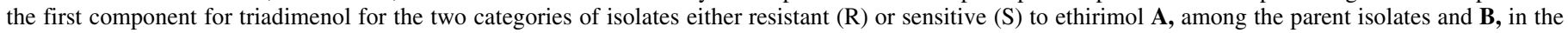
laboratory population. 
and $94 \%$ of the total (Table 2). Increasing Z1 scores reflected higher levels of resistance to triadimenol, indicated by the position of the control isolates on the graph (Fig. 1) and the high correlation between $Z 1$ scores and $\log \mathrm{ED}_{50}$ values $(0.82 ; P=0.001)$. For each test, the tested isolates were grouped in distinct clouds around the control isolates, which allowed the tested parents and the 137 selected progeny isolates to be placed in one of the categories of resistance, using the mean value of the $Z 1$ scores for the control isolates (Table 2). Among the four expected levels of response, similar to DH14 (sensitive), CC66 (low), CC107 (moderate), or E1 (high), our results did not allow reliable discrimination between the sensitive and low categories for all test batches (Table 2); the isolates were thus pooled into the sensitive category for the analysis. Because the relative position of the control isolates was consistent across the batches of test, the results (classification of the tested isolates as resistant, moderately resistant, or sensitive) from the different batches could be combined.

Because no information was previously available about the existing variation in natural populations or the potential categories of response, four isolates were included in both tests for the response to $\mathrm{BTH}$-induced resistance in order to compare results across tests. These four isolates were separated by their scores on the first two principal components of the PCA (Fig. 1; Table 2). Isolates DH14 and CC66 had consistently lower values than isolates CC107 and E1. However, within these groups, the ranking of the isolates was not consistent between the two tests (Table 2). In contrast to the fungicides ethirimol and triadimenol, it was not possible to identify distinct categories of isolates based on the first two principal components of the PCA (Fig. 1). Two arbitrary categories (sensitive and resistant) were defined as $Z 1$ values lower or higher than the mean value of the four isolates, respectively. The correlation between $Z 1$ and $\log \mathrm{ED}_{50}$ values was lower $(0.56 ; P=0.001)$ than for the fungicides.

Assembled laboratory population. In the laboratory population, each pathotype was represented by a single isolate and the number of virulences per isolate ranged from 0 to 13 out of the 14 alleles tested. The parents used for the crosses displayed variation in their response to the two fungicides and to BTH-induced resistance (Fig. 2A) and this variation was kept in the laboratory population (Fig. 2B). The protocol of randomization of the variation by sexual crosses followed by the choice of some progenies allowed keeping variation in the progenies even for some traits not directly taken into account during the choice of ascospore progenies (Fig. 2B). This verification was obtained using the resistance to triadimenol as a control. Some variation for the response was present in the parents ( 7 sensitive isolates, 5 moderately, and 15 highly resistant; Table 1), and the progenies kept while assembling the laboratory population were not chosen according to this trait. Nevertheless, the results of a posteriori testing indicated that the variation was present in the laboratory population, with $\log \mathrm{ED}_{50}$ for triadimenol ranging from 0.89 to 3.93 . Of the 100 isolates assessed, 24 were sensitive (23 resembled DH14 and one had low resistance like CC66), 15 had moderate resistance resembling CC107, and 61 had high resistance like E1. The distributions of isolates in the three triadimenol sensitivity classes were not significantly different $\left(\chi^{2}=2.29 ; \mathrm{df}=2 ; P=0.31\right)$ among the 84 ethirimol-sensitive and the 53 ethirimol-resistant isolates.

For BTH, $\log \mathrm{ED}_{50}$ values ranged from 1.40 to 4.08 for the 95 isolates tested. Even if the confidence in the toxicological test may be limited, the previous result on triadimenol indicated that the variation in response to BTH present among the parents of the crosses (isolates sampled on field plots repeatedly sprayed during the epidemics) is expected to persist in the progenies even if this criterion was not directly used to assemble the laboratory population. In the laboratory population, there was no correlation between the levels of response to ethirimol, triadimenol, and BTH (Fig. 2B), which is a prerequisite to avoid bias due to indirect selection during the generations.

Evolution of the sensitivity to fungicides over generations. The distribution of $\log \mathrm{ED}_{50}$ values in the laboratory population, i.e., in the initial generation, reflected the two categories of response to ethirimol (either sensitive as CC52 or resistant as DH14; Fig. 3), the three categories of response to triadimenol (either sensitive as $\mathrm{DH} 14$ and CC66, moderate resistance as CC107, or resistant as E1; Fig. 3), and the continuous distribution for BTH-induced resistance for which the categories sensitive and resistant were not based on previously identified distinct levels of response (Fig. 3). The frequencies of these categories were summarized over generations for the selection regimes $(\mathrm{C}, \mathrm{B}, \mathrm{EB}, \mathrm{E}$, and ES) and a regression model was fitted to estimate relative fitness of categories (Fig. 4). The likelihood ratio for the comparison between observed and expected data was nonsignificant in most cases (Table 3), indicating that the model fitted the data well.
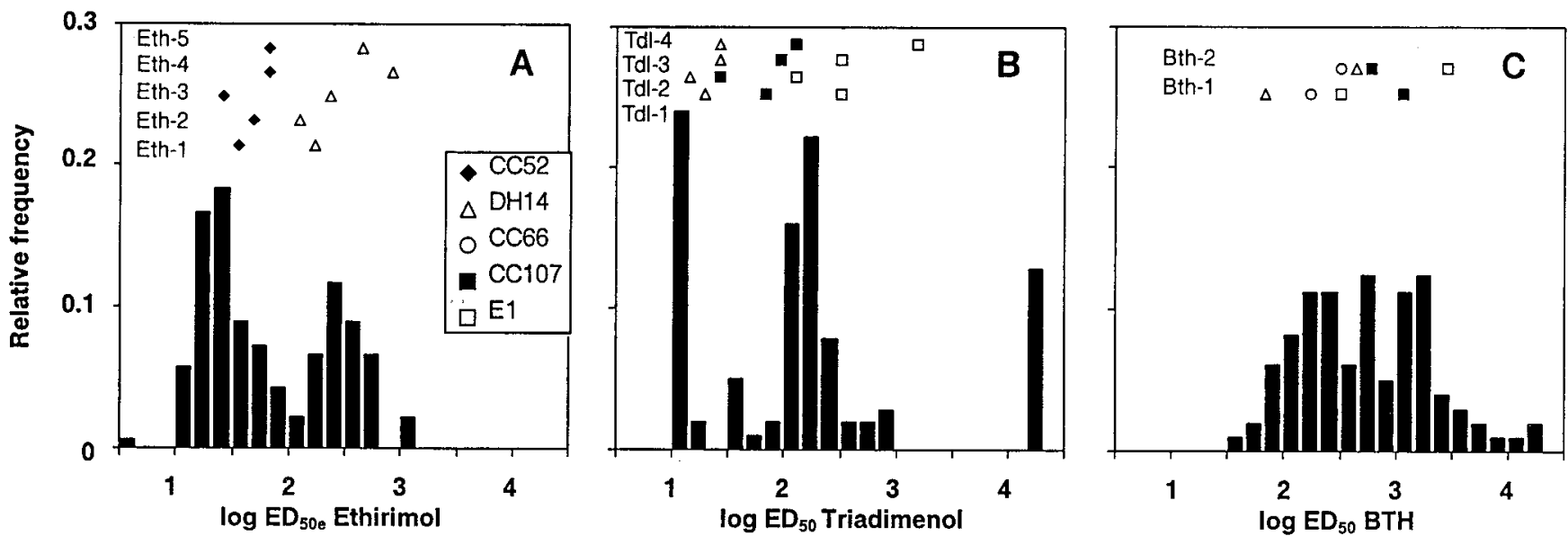

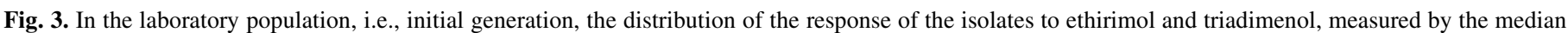

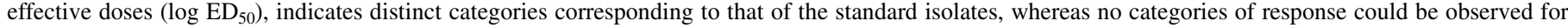

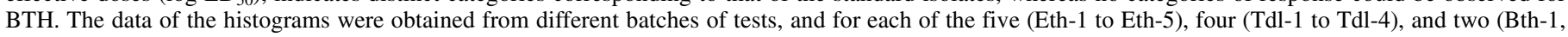

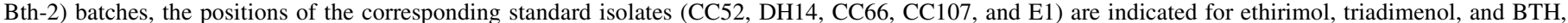

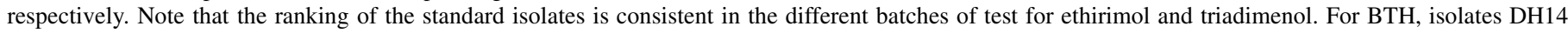

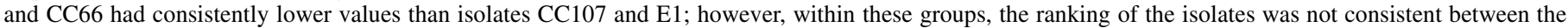
two tests. 
For ethirimol (Fig. 4), the relative fitness of the resistant category was significantly different (confidence interval at the $95 \%$ level not including zero) from the sensitive category (used as a standard within generation) for the six generation boxes treated with ethirimol (regimes EB, E, and ES). In the two boxes treated with BTH (B), the frequency changes were not significant (Table $3)$. In the control regime, the overall change was not significant despite a slight increase of the resistant category in one of the boxes, but not in the other. These results indicate that the use of the fungicide ethirimol specifically induces an increase in frequency over time, leading to a significantly higher relative fitness of the resistant isolates.

For triadimenol, the frequencies of the categories of moderate (M) and high resistance $(\mathrm{H})$, respectively, were compared with the sensitive (S) category (used as a standard within generation). Significant changes were detected in some of the regimes (Fig. 4), but these changes were never significant for both generation boxes of these selection regimes (Table 3). These results indicate the absence of significant frequency changes (due, for example, to drift) in the absence of treatment, i.e., when no evolution is expected.

For the BTH regime, the frequency of the resistant (R) category was compared with the sensitive $(\mathrm{S})$ category (used as a standard within generations). Significant changes were detected in some of the regimes (Fig. 4), but these changes were never significant for both generation boxes of these selection regimes (Table 3 ). In this case, the absence of detection could be due either to the absence of evolution or the failure of the toxicological test to detect such evolution. To test the latter hypothesis, we used the evolution over generations of pathotype diversity in the population as an indirect indicator of the occurrence of a selection pressure.

Evolution of pathotype diversity over generations. In a first analysis, diversity indices were calculated for each box at each generation. However, high and inconsistent variation from one generation to the next made the results difficult to interpret (data not shown). We proposed that part of this variation was due to the high sensitivity of the diversity indices to sample size. To test this hypothesis, we pooled the isolates from two successive generations and calculated the diversity indices for the following samples: Initial (i.e., laboratory population), $\mathrm{G}_{0+2}, \mathrm{G}_{4+6}$, and $\mathrm{G}_{8+10}$ with sample sizes from 33 to 76 isolates per box in $G_{0}$ to $G_{10}$. The results were then consistent over the generations, with a decrease over time for all of the following diversity indices: modified Shannon $\mathrm{Hw}^{\prime}$ from 0.99 toward 0.6 to 0.8 , Shannon evenness $\mathrm{EH}$ from 1 toward 0.81 to 0.94 , and Simpson index $(\lambda)$ from 1 to 0.86 to 0.96 . There was a consistent effect over the two boxes of each regime on the decrease of diversity indices (data not shown). The diversity was highest in the control (C) and BTH (B) regimes, where only drift was influencing the evolution of the population, and lowest for the regime combining the use of ethirimol with the use of BTH (EB). This effect of the selection regime was confirmed by a final analysis made when the samples from the two boxes of each selection regime were pooled (with sample sizes from 80 to 150 isolates in $\mathrm{G}_{0}$ to $\mathrm{G}_{10}$ ) and indices were then calculated with the corresponding confidence interval estimated by the jackknife procedure (Fig. 5; Table 4). For each diversity index, the GLM analysis indicated that the two factors generation and selection regime had a significant effect $(P=0.05)$ on the patho-
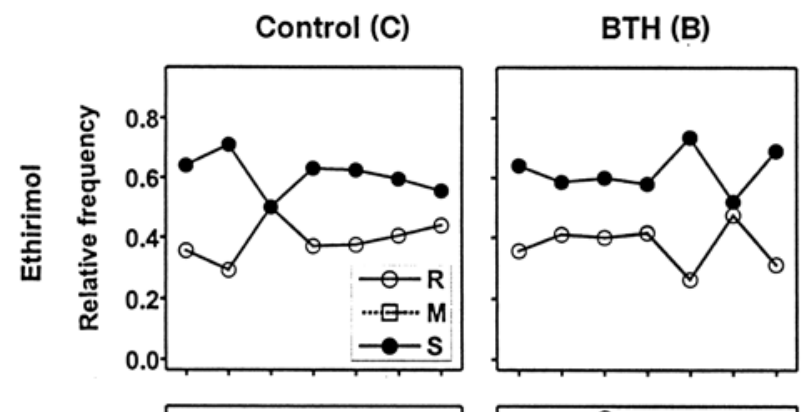

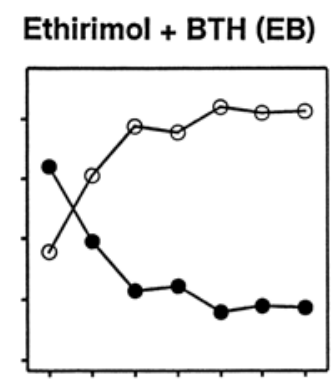

Ethirimol (E)
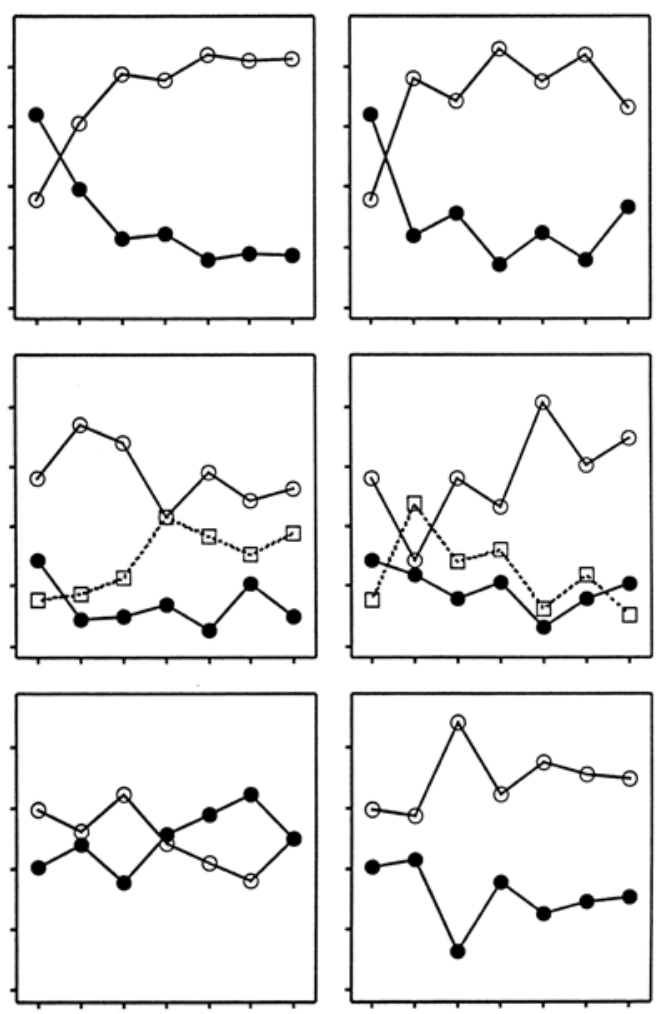

Initial G0 G2 G4 G6 G8 G10

Generation

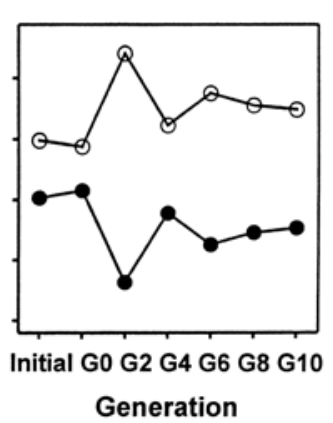

Ethirimol-escape (ES)
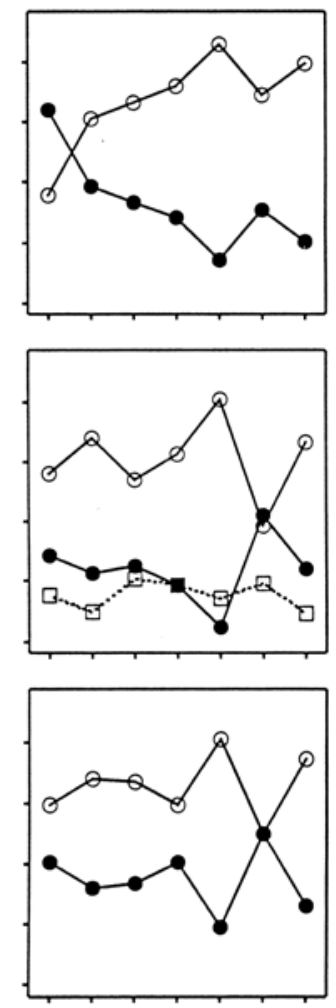

Initial G0 G2 G4 G6 G8 G10

Generation

Fig. 4. Evolution over generations of the resistant (R) and moderately resistant (M) categories compared with the sensitive (S) category for ethirimol, triadimenol, and BTH depending on the selection regime. The application of ethirimol induced a specific response of the population, whereas there was no evolution in the absence of treatment (triadimenol) and no evolution was detected in response to BTH treatment. The control regime (C) was untreated, whereas ethirimol treatments were applied in regimes E, EB, and ES, and BTH treatments were applied in regimes B and EB. Note that for the first generation, data are indicated both before (initial $=$ mixture of isolates that have been inoculated) and after $\left(\mathrm{G}_{0}=\right.$ sampled on the plants at the end of the generation) the selection event. 
type diversity, whereas interactions between factors were not significant. The diversity in the BTH-only (B) regime was not significantly different from that in the control (C) regime indicated by the multiple comparisons (Table 4; Fig. 5). This result supports the toxicological test, and the use of BTH alone does not exert a selection pressure stronger than the random drift. The diversity values were lower in the regimes treated with ethirimol $(\mathrm{E}, \mathrm{EB}$, and ES) than in the control (C) and BTH-only (B) regimes (Fig. $5)$. This result indicates that the occurrence of a selective pressure can cause a larger reduction of the pathotype diversity than drift alone can (Table 4). The diversity values were lower in the regime treated with ethirimol in combination with BTH (EB) than in the ethirimol-only (E) regime (Fig. 5), and this comparison was significant for two of the diversity indices (Shannon evenness EH, Simpson index $\lambda$ ) but not for the last one (Shannon index $\mathrm{Hw}^{\prime}$ ) (Table 4). This result contradicts the toxicological tests, and the use of BTH in addition to ethirimol exerts a stronger selection pressure than ethirimol alone.

\section{DISCUSSION}

Variation in the initial population. The two approaches commonly described to introduce variation corresponding to the selection pressure to be exerted in the laboratory populations are the use of (i) pairs (21) or a low number (25) of well-characterized isolates or (ii) a large number of isolates collected from natural populations, of which only a sample was characterized (22). But the experiment reported here was intended to address the question before the loss of efficacy of the plant protection measure was observed in the field, i.e., when a toxicological test was not reliable and resistant isolates were not yet available in collections. We collected isolates from field plots repeatedly treated with BTH

TABLE 3. Relative fitness $\left(e^{X}\right)$ of resistant isolates in the 10 generation boxes ${ }^{\mathrm{w}}$

\begin{tabular}{|c|c|c|c|c|c|c|c|c|c|}
\hline & \multicolumn{3}{|c|}{ Model fit } & \multicolumn{6}{|c|}{ Regression slope ${ }^{\mathrm{x}}$} \\
\hline & Box $^{y}$ & $\chi^{2}$ & $P$ & $X$ & $e^{X}$ & SE & $Z^{Z}$ & $\geq 95 \% \mathrm{CI}$ & $\leq 95 \%$ CI \\
\hline \multicolumn{10}{|c|}{ Ethirimol } \\
\hline \multirow[t]{2}{*}{$\mathrm{EB}$} & $\mathrm{a}$ & 10.96 & 0.05 & 0.71 & 2.04 & 0.12 & $5.88^{*}$ & 0.48 & 0.95 \\
\hline & $\mathrm{b}$ & 5.93 & 0.31 & 0.28 & 1.32 & 0.07 & $3.75^{*}$ & 0.13 & 0.42 \\
\hline \multirow[t]{2}{*}{$\mathrm{E}$} & $\mathrm{a}$ & 17.87 & 0.00 & 0.26 & 1.30 & 0.07 & $3.68 *$ & 0.12 & 0.40 \\
\hline & $\mathrm{b}$ & 8.62 & 0.13 & 0.45 & 1.57 & 0.10 & $4.59 *$ & 0.26 & 0.65 \\
\hline \multirow[t]{2}{*}{ B } & $\mathrm{a}$ & 5.46 & 0.36 & -0.01 & 0.99 & 0.07 & -0.08 & -0.15 & 0.13 \\
\hline & $\mathrm{b}$ & 1.59 & 0.90 & 0.01 & 1.01 & 0.09 & 0.06 & -0.17 & 0.18 \\
\hline \multirow[t]{2}{*}{$\mathrm{C}$} & $\mathrm{a}$ & 0.88 & 0.97 & -0.02 & 0.98 & 0.07 & -0.32 & -0.16 & 0.11 \\
\hline & $\mathrm{b}$ & 3.19 & 0.67 & 0.15 & 1.16 & 0.08 & $2.00 *$ & 0.00 & 0.30 \\
\hline \multirow[t]{2}{*}{ ES } & $\mathrm{a}$ & 9.43 & 0.09 & 0.22 & 1.24 & 0.07 & $2.96^{*}$ & 0.07 & 0.36 \\
\hline & $\mathrm{b}$ & 23.60 & 0.00 & 0.44 & 1.55 & 0.09 & $5.06^{*}$ & 0.27 & 0.61 \\
\hline \multicolumn{10}{|c|}{ Triadimenol } \\
\hline \multirow[t]{4}{*}{ EB } & $\mathrm{a}-\mathrm{M}$ & 17.50 & 0.06 & 0.41 & 1.50 & 0.11 & $3.80 *$ & 0.20 & 0.61 \\
\hline & $\mathrm{a}-\mathrm{R}$ & & & 0.02 & 1.02 & 0.10 & 0.20 & -0.18 & 0.23 \\
\hline & b-M & 13.23 & 0.21 & 0.12 & 1.13 & 0.13 & 0.92 & -0.14 & 0.38 \\
\hline & b-R & & & 0.20 & 1.22 & 0.10 & $1.98 *$ & 0.00 & 0.39 \\
\hline \multirow[t]{4}{*}{$\mathrm{E}$} & $\mathrm{a}-\mathrm{M}$ & 23.17 & 0.01 & 0.07 & 1.08 & 0.10 & 0.74 & -0.12 & 0.27 \\
\hline & $a-R$ & & & 0.10 & 1.11 & 0.08 & 1.29 & -0.05 & 0.26 \\
\hline & b-M & 17.43 & 0.07 & 0.10 & 1.11 & 0.13 & 0.82 & -0.14 & 0.35 \\
\hline & b-R & & & 0.17 & 1.18 & 0.11 & 1.58 & -0.04 & 0.37 \\
\hline \multirow[t]{4}{*}{ B } & $\mathrm{a}-\mathrm{M}$ & 29.86 & 0.00 & -0.20 & 0.82 & 0.22 & -0.90 & -0.63 & 0.24 \\
\hline & $a-R$ & & & 0.16 & 1.17 & 0.09 & 1.69 & -0.03 & 0.34 \\
\hline & b-M & 9.19 & 0.51 & 0.07 & 1.08 & 0.14 & 0.53 & -0.20 & 0.35 \\
\hline & $b-R$ & & & 0.11 & 1.12 & 0.11 & 1.02 & -0.10 & 0.32 \\
\hline \multirow[t]{4}{*}{$\mathrm{C}$} & $\mathrm{a}-\mathrm{M}$ & 19.08 & 0.04 & 0.19 & 1.21 & 0.15 & 1.27 & -0.10 & 0.48 \\
\hline & $a-R$ & & & 0.18 & 1.19 & 0.09 & $2.02 *$ & 0.01 & 0.35 \\
\hline & b-M & 10.17 & 0.43 & 0.13 & 1.14 & 0.16 & 0.80 & -0.19 & 0.45 \\
\hline & b-R & & & 0.25 & 1.29 & 0.11 & $2.37 *$ & 0.04 & 0.46 \\
\hline \multirow[t]{4}{*}{ ES } & $\mathrm{a}-\mathrm{M}$ & 10.24 & 0.42 & 0.09 & 1.09 & 0.11 & 0.78 & -0.13 & 0.30 \\
\hline & $a-R$ & & & 0.06 & 1.06 & 0.09 & 0.64 & -0.12 & 0.23 \\
\hline & b-M & 18.06 & 0.05 & -0.08 & 0.93 & 0.11 & -0.73 & -0.29 & 0.13 \\
\hline & b-R & & & 0.02 & 1.02 & 0.07 & 0.22 & -0.12 & 0.16 \\
\hline \multicolumn{10}{|l|}{ ВTH } \\
\hline \multirow[t]{2}{*}{ EB } & $\mathrm{a}$ & 4.76 & 0.45 & -0.27 & 0.77 & 0.07 & $-3.63^{*}$ & -0.41 & -0.12 \\
\hline & $\mathrm{b}$ & 10.85 & 0.05 & 0.00 & 1.00 & 0.07 & 0.03 & -0.13 & 0.14 \\
\hline \multirow[t]{2}{*}{$\mathrm{E}$} & $\mathrm{a}$ & 4.58 & 0.47 & -0.03 & 0.98 & 0.07 & -0.39 & -0.15 & 0.10 \\
\hline & b & 12.99 & 0.02 & 0.37 & 1.44 & 0.12 & $3.03 *$ & 0.13 & 0.60 \\
\hline \multirow[t]{2}{*}{ B } & $\mathrm{a}$ & 2.75 & 0.74 & 0.03 & 1.04 & 0.07 & 0.49 & -0.10 & 0.17 \\
\hline & $\mathrm{b}$ & 3.45 & 0.63 & 0.07 & 1.07 & 0.09 & 0.81 & -0.10 & 0.25 \\
\hline \multirow[t]{2}{*}{$\mathrm{C}$} & $\mathrm{a}$ & 4.18 & 0.52 & 0.00 & 1.00 & 0.07 & -0.01 & -0.13 & 0.13 \\
\hline & $\mathrm{b}$ & 7.05 & 0.22 & 0.04 & 1.04 & 0.08 & 0.45 & -0.12 & 0.19 \\
\hline \multirow[t]{2}{*}{$\mathrm{ES}$} & $\mathrm{a}$ & 11.60 & 0.04 & 0.16 & 1.18 & 0.08 & $1.97 *$ & 0.00 & 0.32 \\
\hline & b & 4.04 & 0.54 & 0.03 & 1.03 & 0.06 & 0.45 & -0.10 & 0.15 \\
\hline
\end{tabular}

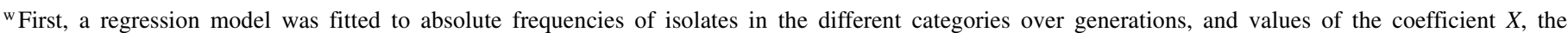
calculated slope value $e^{X}$, standard error of the $X$ value (SE), and goodness of fit of the model to the data (chi-square and associated probability $P$ ) are indicated.

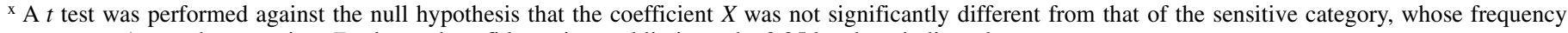
was set to 1 at each generation. $Z$ value and confidence interval limits at the 0.95 level are indicated.

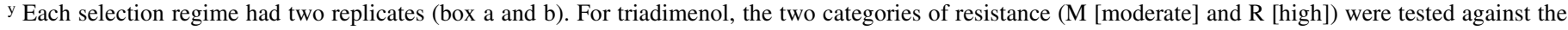
sensitive (S). The control regime (C) was untreated, whereas ethirimol treatments were applied in regimes E, EB, and ES, and BTH treatments were applied in regimes $\mathrm{B}$ and $\mathrm{EB}$.

${ }^{\text {z }}$ Significant evolution (*), i.e., $Z$ different from 0 at the $5 \%$ level. 
during the epidemics, following the hypothesis that if the inducer does exert a selection pressure, repeated treatments would induce an increase in frequency of less sensitive isolates, as reported following ethirimol $(26)$ or triadimenol $(6,35)$ treatments. Consequently, the limit of our protocol is that only the detection of an evolution could lead to a conclusion, because the absence of evolution could also be due to insufficient variation in the initial population.

Once the source of variation was chosen, we randomized the background of the isolates with respect to the selected traits. Controlled crosses among the parent isolates and the choice of some of the progeny isolates allowed us to obtain a population in which the desired traits, i.e., response to ethirimol, triadimenol, and BTH, were independent from one another in the population. Our results are in agreement with the two previous studies in which controlled crosses were used in wheat leaf rust (15) and wheat mildew (2), indicating that sexual reproduction increases diversity and reduces the linkage between traits (15). This allows a reduction in the total size of a laboratory population and hence in the effort required for the corresponding pathotype characterization. Using the resistance to triadimenol as a reporter trait, we have verified that the diversity present in the parents remained in the population of progenies, even if these were not directly chosen for this trait. This allowed us to assume that the variation present in the parents of the crosses for response to the inducer BTH was not lost during the randomization procedure. These results indicate that the use of generation experiments can be extended to cases where the baseline sensitivity of the population is not yet known, and that the use of crosses might then be an efficient way to randomize the variability, even for traits that cannot be reliably tested for.

Response to the selection pressures: evaluation of the protocol used. The response to ethirimol was used as a positive control to ensure that an evolution specifically induced by a selection regime would be detected. As with previous experiments (25), the use of ethirimol at a dose not lethal for the sensitive isolates (Table 2) clearly led to a strong selection pressure and specifically induced an increase in frequency of isolates resistant to ethirimol over time in the ethirimol-treated boxes in contrast to the control boxes. The most significant changes occurred from the initial to the second generation $\left(\mathrm{G}_{2}\right)$, which was much faster than the changes observed by O'Hara et al. (22) for fenpropimorph. These authors suggested the variability in the applied dose as a possible explanation for the slow increase. Predictions drawn from a simulation model (31) also suggested that increasing the dose variability would lead to a reduced selection pressure and therefore slow down the increase in average resistance. In the ethirimol-

TABLE 4. Multiple comparison of means of selection regimes of the modified Shannon $\left(\mathrm{Hw}^{\prime}\right)$, Shannon evenness $(\mathrm{EH})$, and Simpson $(\lambda)$ diversity indices

\begin{tabular}{lcl}
\hline Diversity index & Selection regime & Mean $^{\mathrm{z}}$ \\
\hline $\mathrm{Hw}^{\prime}$ & $\mathrm{B}$ & $0.69 \mathrm{a}$ \\
& $\mathrm{C}$ & $0.67 \mathrm{ab}$ \\
& $\mathrm{E}$ & $0.62 \mathrm{~b}$ \\
& $\mathrm{ES}$ & $0.61 \mathrm{bc}$ \\
$\mathrm{EH}$ & $\mathrm{EB}$ & $0.58 \mathrm{bc}$ \\
& $\mathrm{C}$ & $0.91 \mathrm{a}$ \\
& $\mathrm{B}$ & $0.90 \mathrm{a}$ \\
& E & $0.88 \mathrm{a}$ \\
$\lambda$ & ES & $0.86 \mathrm{~b}$ \\
& EB & $0.84 \mathrm{~b}$ \\
& $\mathrm{C}$ & $0.97 \mathrm{a}$ \\
& B & $0.97 \mathrm{a}$ \\
& ES & $0.96 \mathrm{a}$ \\
& E & $0.95 \mathrm{a}$ \\
& EB & $0.94 \mathrm{~b}$ \\
\hline
\end{tabular}

${ }_{\mathrm{z}}$ Means followed by the same value are not significantly different $(P=0.05)$ by multiple comparisons using Dunnett T3.
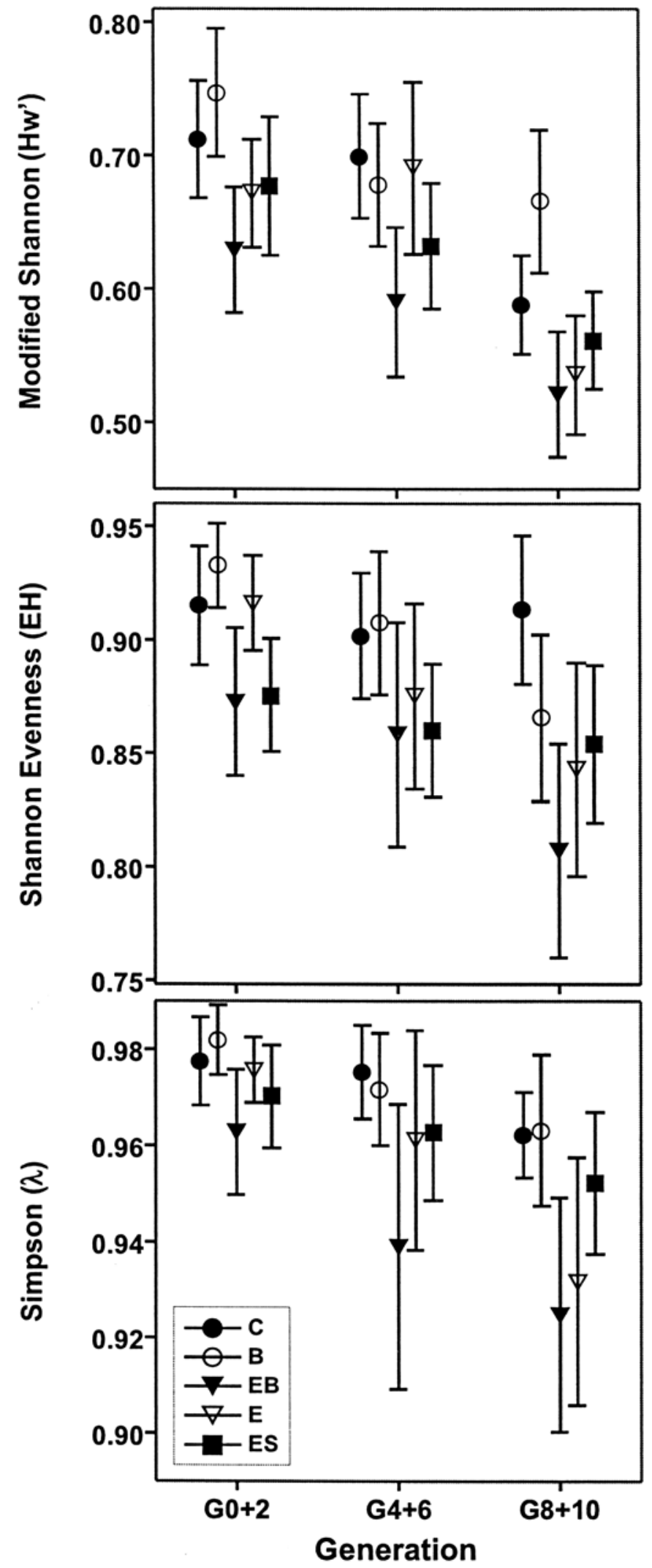

Fig. 5. Over the 10 generations of recurrent selection, the decrease in pathotype diversity in the population due to random drift $(\mathrm{C})$ was reinforced by the effect of selection pressures when ethirimol (E, EB, and ES) and BTH (EB) were applied. The pathotype diversity was measured by the modified Shannon $\left(\mathrm{Hw}^{\prime}\right)$, Shannon evenness $(\mathrm{EH})$, and Simpson $(\lambda)$ indices. Pseudovalues of the diversity indices and their confidence intervals based on estimates of the standard error were obtained by the jackknife (resampling) procedure. The results of multiple comparison tests are presented in Table 4. 
treated selection regime in which escape was allowed (ES), we simulated increased variability in the dose by allowing $10 \%$ of each generation to escape from the treatment on untreated plants and contribute spores to the next generation. However, no significant differences in the increase were detected between the ethirimol-treated boxes (EB and E) and the escape boxes (ES). This was interpreted as an indication that the percentage of escape was not sufficient compared with the strength of the selective pressure needed to give rise to differences in evolution that could be detected by our protocol.

We used the response to triadimenol as a negative control to ensure that no evolution would be detected if the traits were not selected for. As expected in the absence of triadimenol treatments, under random drift the average resistance of the populations to triadimenol did not show any consistent evolution over generations and replicated boxes. Because there were sensitive isolates in our laboratory population, we consider the alternate hypothesis, that the initial variation was not sufficient in the laboratory population to give rise to a detectable change as previously observed in field experiments including triadimenol treatments (26), an unlikely one. We interpreted the results of our positive and negative control regimes as an indication that when standard isolates are available, the protocol used is suitable to detect the effect of selection pressures, because evolution specifically induced by ethirimol was detected and no evolution was observed for the unselected trait.

No response to $\mathrm{BTH}$-induced resistance was detected by toxicological tests. The average response of the populations to BTH application did not show any consistent evolution over generations and replicated boxes, even when BTH treatments were applied. We rejected the hypothesis that BTH application had no effect on barley powdery mildew, because in wheat and spring barley (29) BTH-induced gene expression led to induced resistance against powdery mildew. Furthermore, in a field experiment, the severity of powdery mildew epidemics was reduced on barley fields treated with BTH compared with untreated fields (14). We examined the hypothesis that the toxicological test used to assess the sensitivity of the isolates was not appropriate. We formulated this hypothesis because in our sensitivity tests, the number of colonies observed on the leaves decreased with increasing doses of $\mathrm{BTH}$, and it was possible to calculate $\log \mathrm{ED}_{50}$ values. However, in contrast to the ethirimol and triadimenol tests, the isolates tested in both batches did not show a consistent ranking on the two first principal components of the PCA or for $\log \mathrm{ED}_{50}$ values. This indicates that at least some variability in the response was due to the test. In our results, it was not possible to identify categories of response among the isolates. One reason for this might be the influence of the variability due to the test (3), because it was already observed that for the fungicides ethirimol $(5,10)$, triadimenol (5), and fenpropimorph (22), the detection (or not) of categories depends on the testing. Because of the lack of standard isolates and the likelihood of errors caused by the testing, our results from the sensitivity tests do not allow conclusions to be drawn regarding the existence of variability in the response to BTH among isolates; hence, we used diversity indices as an indirect indication for the existence of a selection pressure.

Existence of a selection pressure due to BTH-induced resistance detected by changes in pathotype diversity. The rationale for using the diversity in pathotypes as an indirect indication of the existence of a selection pressure is that in surveys of natural populations (28), field experiments (34), and competition experiments $(15,22)$, selection pressure decreases the diversity of pathogen populations, whereby the magnitude of the decrease depended on the strength of the selection applied. In our experiment, the diversity decreased over generations in all boxes, including the untreated control; drift might have contributed to this decrease. However, even though not all comparisons were significant, the diversity was more greatly reduced in the ethirimol-treated boxes than in the boxes not treated with ethirimol. This is in agreement with the fungicide sensitivity tests which indicated the occurrence of a selection for increased ethirimol resistance. For two of the diversity indices used, the diversity was significantly lower in the two boxes treated with ethirimol in combination with BTH (EB) than in ethirimol boxes (E), and this result can be interpreted as an indication that the selection pressure was stronger in the former case than in the latter. The hypothesis that the difference in response to selection could be due to differences in the composition of the population in the initial generation was discarded because the protocol used ensured that the same pathotypes were present in similar frequencies in all the boxes. We therefore interpreted the results as an indication that in some cases application of BTH contributed to a selection pressure. However, the selection pressure from BTH may not be strong enough to be detected in all the cases, because when BTH-treated boxes (B) were compared with the control boxes $(\mathrm{C})$, the rates of evolution of diversity were not different. This indicates that if BTH induced a selection pressure among the ethirimol-resistant isolates, the same effect was not large enough to be detected when selection was exerted on both ethirimol-resistant and ethirimol-sensitive isolates. An alternate explanation for these observations could be a synergy between the effects of ethirimol and BTH. The detection of some selective effects with such a simple protocol (variation introduced from treated fields, precision of the detection) indicates that the hypothesis that BTH has no selective effects should be reconsidered until more data are available.

Consequences for the use of BTH in plant protection. One important question is to what extent these results obtained under controlled conditions can be extrapolated to the field. Selective forces will be different because the controlled temperature, regular inoculum density, and regular transfer to new leaves create very different conditions in the generation boxes to those in the field. During a yearly epidemic, fluctuating climatic conditions and infection density along with the aging of the plants all have an influence on the development of powdery mildew $(7,21,23)$. The application of BTH is also different, as the manufacturer of Bion (Novartis AG/Ciba Geigy AG, Basel, Switzerland) recommends using this chemical only once a year and switching to usual fungicides if disease control is insufficient. Differences in the response to BTH were already detected under controlled conditions depending on the presence of the additional selection pressure exerted by ethirimol. In the field, where selection pressures are not constant, pathogen populations are larger and may include a wider range of sensitivity; one could reasonably expect even more variation in the response to BTH. Our results indicate that although resistance inducers do not act directly on the pathogen, but rather through activation of the plant defense mechanisms, this does not remove the risk of adaptation of the pathogen population in all cases. This somewhat contradicts a previous statement about BTH from Ruess et al. (29) who reported that due to BTH's particular mode of action, the development of resistance in pathogens seems very unlikely. This study indicates that wide and careless use of this chemical in the field might also lead to breakdown of its efficacy and should hence be avoided before more information is available.

\section{ACKNOWLEDGMENTS}

We thank B. Reinhardt for technical assistance, R. Snowdon for helpful comments on a previous version of the manuscript, L. Munk (Royal Agricultural and Veterinary University, Copenhagen) for providing the seeds of the Pallas near-isogenic lines, and J. K. M. Brown (John Innes Centre, Norwich) and E. Limpert (ETH, Zurich) for providing collection isolates.

\section{LITERATURE CITED}

1. Blatter, R. H. E., Brown, J. K. M., and Wolfe, M. S. 1998. Genetic control of the resistance of Erysiphe graminis $\mathrm{f}$. sp. hordei to five triazoles 
fungicides. Plant Pathol. 47:570-579.

2. Bronson, C. R., and Ellingboe, A. H. 1986. The influence of four unnecessary genes for virulence on the fitness of Erysiphe graminis f. sp. tritici. Phytopathology 76:154-158.

3. Brown, J. K. M. 1991. Statistical analysis of the response of powdery mildews to fungicides. Pages 161-175 in: Integrated Control of Cereal Mildews: Virulence Patterns and Their Change. J. H. Jørgensen, ed. Ris $\emptyset$ National Laboratory, Roskilde, Denmark.

4. Brown, J. K. M., Foster, E. M., and O'Hara, R. B. 1997. Adaptation of powdery mildew populations to cereal varieties in relation to durable and non-durable Resistance. Pages 119-138 in: The Gene-for-Gene Relationship in Host-Parasite Interactions. I. R. Crute, E. B. Holub, and J. J. Burdon, eds. CAB International, Oxon.

5. Brown, J. K. M., Jessop, A. C., Thomas, S., and Rezanoor, H. N. 1992. Genetic control of the response of Erysiphe graminis f. sp. hordei to ethirimol and triadimenol. Plant Pathol. 41:126-135.

6. Brown, J. K. M., and Wolfe, M. S. 1991. Levels of resistance of Erysiphe graminis f. sp. hordei to the systemic fungicide triadimenol. Neth. J. Plant Pathol. 97:251-263.

7. Eckhardt, H., Steubing, L., and Kranz, J. 1987. Das Koloniewachstum von Erysiphe graminis DC. f. sp. hordei Marchal in Abhängigkeitvon Temperatur und Insertionshöhe der Blätter. Angew. Bot. 58:433-443.

8. Goodwin, S. B., Spielman, L. J., Matuszak, J. M., Bergeron, S. N., and Fry, W. E. 1992. Clonal diversity and genetic differentiation of Phytophthora infestans populations in northern and central Mexico. Phytopathology 82:955-961.

9. Görlach, J., Volrath, S., Knauf-Beiter, G., Hengy, G., Beckove, U., Kogel, K. H., Oostendorp, M., Staub, T., Ward, E., Kessman, H., and Ryals, J. 1996. Benzothiadiazole, a novel class of inducers of systemic acquired resistance, activates gene expression and disease resistance in wheat. Plant Cell 8:629-643.

10. Hollomon, D. W. 1981. Genetic control of ethirimol resistance in a natural population of Erysiphe graminis f. sp. hordei. Phytopathology 71:536-540.

11. Hovmøller, M. S., Caffier, V., Jalli, M., Andersen, O., Besenhofer, G., Czembor, J. H., Dreiseitl, A., Flath, K., Fleck, A., Heinrics, F., Jonsson, R., Limpert, L., Mercer, P., Plesnik, S., Rashal, I., Skinnes, H., Slater, S., and Vronska, O. 2000. The European barley powdery mildew virulence survey and disease nursery 1993-1999. Agronomie 20:729-743.

12. Johnson, R. 1984. A critical analysis of durable resistance. Annu. Rev. Phytopathol. 22:309-330.

13. Jørgensen, J. H. 1988. Erysiphe graminis, powdery mildew of cereals and grasses. Adv. Plant Pathol. 6:137-157.

14. Knecht, C., Pons, J., and Köhler, W. 1999. Does systemically induced resistance (SAR) cause selection pressure in barley powdery mildew populations? Workshop on Disease Resistance and Cereal Leaf Pathogens Beyond the Year 2000. Cost 817 Action: Population Structure of Airborne Pathogens on Cereals. Martina Franca, Italy.

15. Kolmer, J. A. 1993. Selection in a heterogeneous population of Puccinia recondita f. sp. tritici. Phytopathology 83:909-914.

16. Kølster, P., Munk, L., Stølen, O., and Løhde, J. 1986. Near-isogenic barley lines with genes for resistance to powdery mildew. Crop Sci. 26:903-907.

17. Leonard, K. J. 1994. Stability of equilibria in a gene-for-gene co- evolution model of host-parasite interactions. Phytopathology 84:70-77.

18. Löwer, C. 1999. Koevolution in Hordeum spontaneum und Erysiphe graminis f. sp. hordei in populationen der Westtürkei. Ph.D. Thesis. University of Giessen, Germany.

19. Lynkjær, M. F., Newton, A. C., Aztema, J. L., and Baker, S. J. 2000. The barley mlo-gene: An important powdery mildew resistance source. Agronomie 20:745-756.

20. Moseman, J. G., Macer, R. C. F., and Greeley, L. W. 1965. Genetic studies with cultures of Erysiphe graminis f. sp. hordei virulent on hordeum spontaneum. Trans. Br. Mycol. Soc. 48:479-489.

21. O'Hara, R. B., and Brown, J. K. M. 1996. Frequency- and densitydependent selection in wheat powdery mildew. Heredity 77:439-447.

22. O'Hara, R. B., Nielsen, B. J., and Østergård, H. 2000. The effect of fungicide dose on the composition of laboratory populations of barley powdery mildew. Plant Pathol. 49:558-566.

23. Ohl, L., and Kranz, J. 1989. Untersuchungen zur Pathotypendynamik von Erysiphe graminis f. sp. hordei. Mededelingen van de Faculteit Landbouwwetenschappen. Rijksuniversiteit Gent 54:537-544.

24. Østergård, H. 1987. Estimating relative fitness in asexually reproducing plant pathogen populations. Theor. Appl. Genet. 74:87-94.

25. Pons, J., and Hau, B. 1991. Buildup of triadimenol resistant subpopulations of barley powdery mildew in generation experiments. Pages 135143 in: Integrated Control of Cereal Mildews: Virulence Patterns and Their Change. J. H. Jørgensen, ed. Ris $\varnothing$ National Laboratory, Roskilde, Denmark.

26. Pons-Kühnemann, J. 1994. Struktur und dynamik der Fungizidresistenz in populationen von Erysiphe graminis f. sp. hordei bei verschidenen Applikationsstrategien mit triadimenol und ethirimol. Ph.D. Thesis. University of Giessen, Germany.

27. Quenouille, M. H. 1956. Notes on bias in estimation. Biometrika 43:353-360.

28. Roelfs, A. P., and Groth, J. V. 1980. A comparison of virulence phenotypes in wheat stem rust populations reproducing sexually and asexually. Phytopathology 70:855-862.

29. Ruess, W., Mueller, K., Knauf-Beiter, G., Kunk, W., and Staub, T. 1996. Plant activator CGA 245704: An innovative approach for disease control in cereals and tobacco. Pages 53-60 in: Brighton 1996 Conf. Pest Dis. British Crop Prot. Council, Farnham, UK.

30. Shannon, C. E., and Weaver, W. 1949. The Mathematical Theory of Communication. University of Illinois Press, Urbana.

31. Shaw, M. W. 2000. Models of the effect of dose heterogenity and escape on selection pressure for pesticide resistance. Phytopathology 90:333-339.

32. Simpson, E. H. 1949. Measurement of diversity. Nature 163:688.

33. Tukey, J. 1958. Bias and confidence in not quite large samples. (Abstr.) Ann. Math. Stat. 29:614.

34. Welz, H. G., Nagarajan, S., and Kranz, J. 1990. Short-term virulence dynamics of Erysiphe graminis f. sp. hordei in a single epidemic on two susceptible barley cultivars. Z. Pflanzenkrankh. Pflanzenschutz 97:250262.

35. Wolfe, M. S. 1985. Dynamics of the response of barley mildew to the use of sterol synthesis inhibitors. EPPO Bull. 15:451-457.

36. Wolfe, M. S., and McDermott, J. M. 1994. Population genetics of plant pathogen interactions: The example of the Erysiphe graminis-Hordeum vulgare pathosystem. Annu. Rev. Phytopathol. 32:89-113. 